\title{
Antecedents of Conflict in Marketing's Cross-Functional Relationship with Sales
}

\section{Structured Abstract}

Keywords: Cross-functional relationships, Marketing and Sales dyad, interpersonal conflict, two-country sample: UK and Australia.

\section{Study Purpose}

1. To develop and test a model of the factors which explain the level of interpersonal conflict between Marketing Managers and Sales Managers.

2. To establish the overall level of interpersonal conflict in the full sample and in the two sampled countries.

\section{Design}

We drew on two theoretical frameworks to develop our model - structural contingency theory and the interaction approach. More specifically, our conceptual framework uses three groups of variables to explain interpersonal conflict: structural, individual, and communication. Importantly, we developed and tested nine hypotheses. Confirmatory factor analysis was used to test the validity of the measures while OLS regression was used in testing the hypotheses. The data was collected from 200 Sales Managers in the UK and Australia.

\section{Findings}

Overall, we found that there was a surprisingly low level of interpersonal conflict between MMs and SMs and that there were no differences across the two countries. Of the three groups of variables, the two communication variables - frequency and bidirectionality - had the strongest effects on interpersonal conflict. The next strongest effects were from the individual-level variables - psychological distance and the SM's formal education. The findings also reveal that the level of the SM's marketing training and the MM's sales experience had no influence on interpersonal conflict. Two of the three structural variables use of lateral linkages and being part of a corporation - had the hypothesized negative impact on interpersonal conflict.

\section{What is new?}

Ours is the first study to use a large empirical survey to examine the marketing and sales dyad. Also, ours is one of the few studies to test the effects of communication behaviours on peer manager conflict. 


\section{Introduction}

Integration between marketing and other departments is an area of growing academic and managerial importance. Recent studies examining marketing's cross-functional relationships (Houston et al., 2001), and work examining cross-functional product development teams (Sarin and Mahajan, 2001), underline the importance of this topic.

Our research examines marketing's cross-functional relationship (CFR) with sales, and was chosen because it remains largely unexplored in the literature. In their summary of the sparse literature on the Marketing/Sales CFR, Dewsnap and Jobber $(2000,2002)$ note that the CFR is characterized by mainly negative outcomes, e.g., a lack of cohesion, distrust, dissatisfaction, and conflict. However, because this literature is mostly exclusively anecdotal, conceptual, or normative, it has not quantified these outcomes. Our research begins to fill this gap by focusing on one of these negative outcomes-interpersonal conflict. Management researchers have long recognised the importance of interpersonal conflict within organizations, and many theorists regard conflict as inevitable (Pondy, 1967). Accordingly, conflict has been studied extensively in marketing (e.g., Maltz and Kohli, 2000; Reid et al., 2004) but not in the context examined here.

We draw on two theoretical frameworks to develop our model-structural contingency theory (e.g., Pfeffer, 1982), and the interaction approach (e.g., Morgan and Hunt, 1994). Structural contingency theory posits that firms need to maintain a fit between their strategy and their organizational structure or they will suffer lower performance. Organizational "structure" includes authority relationships, reporting relationships, behaviours required by organizational rules, and patterns of communication (Donaldson, 1996), and includes both the officially prescribed formal organization, and the unofficial, informal organization (Pennings, 1992).

The sample of firms used to test our model exhibit two important structural contingencies. First, they are large, and hence the imperative for these firms to specialise and differentiate their workforce is high. Second, most operate under conditions of high task uncertainty, as the majority of the firms pursued a differentiation strategy ${ }^{i}$. These contingencies provide the management of our responding firms with incentive to develop appropriate organizational structures to improve performance. Here, we examine the effects of three structural variables. The first two relate to management initiatives (i.e., the use of lateral linkage devices; merging the firm's sales and marketing units) while the third (whether or not the firm is part of a large corporation) is best described as a situational structural contingency variable.

Our second theoretical framework - the "interaction approach" seeks to understand and explain the nature and pattern of interactions between personnel in different departments (e.g., Moenaert et al., 1994; Ruekert and Walker, 1987). Managers with behavioural repertoires consistent with the interaction approach tend to encourage more interpersonal interaction and communication, and attempt to increase integration and decrease conflict via more meetings, greater cross-functional information flow, and documented information exchange (Kahn and Mentzer, 1998). Drawing on the interaction approach, we include two communication variables-communication frequency and bidirectional communication, because communication is important in driving CFR performance.

In this article, we make six important contributions to the literature. First, whilst many studies model conflict as an independent or mediating variable (e.g., Gobeli et al., 1998; Menon et al., 1996), we treat it as an outcome variable. Because conflict has potent impacts on CFRs, it is important to examine the antecedents of conflict. Second, our study spans two levels of analysis, and by doing this we provide insights into the relative contributions of structural and individual level constructs to Marketing/Sales conflict. Third, ours is one of the few studies to test the effects of communication behaviours on peer manager conflict. Whilst 
there are theoretical links between communication and conflict, few studies have empirically tested the relationship between these constructs. Our fourth contribution relates to our use of structural contingency theory and the interaction approach as theoretical frameworks. This allowed us to choose a wide range of explanatory variables, and demonstrate to the complementarity of these frameworks. Our specific contribution regarding the Marketing/Sales CFR is that we identify a number of individual characteristics affecting conflict between MMs and SMs, specifically, the psychological distance between the MM and SM, and the level of the SM's formal education. Finally, the two previous academic empirical studies of sales/marketing CFR (Cespedes 1993; 1994) used small samples and intensive interviews to identify the key issues. In contrast, our study was based on a much larger cross-section of firms (sample size $=200$ ) and we collected data across several industry sectors in two countries (UK and Australia). This approach was adopted to provide more generalizable findings.

\section{Conceptual framework}

Our conceptualization uses three groups of variables to explain interpersonal conflict: structural, individual, and communication. We include structural variables because they are cogent and indispensable in organization theory, and topics such as organizational performance cannot even be discussed unless the organization is examined at a collective level (e.g., see Donaldson, 1985, 1996). However, while structural contingency theory establishes the salience of organizational variables, Pennings (1992) argues that focusing on the organization as a whole means there is an absence of analysis at the level of the human actors. We therefore include a number of individual-level variables in our model. We also include two interpersonal communication variables because they capture important individual-level interactions between managers. Figure 1 identifies the nine explanatory variables and shows their hypothesized effects on interpersonal conflict.

\section{[Take in Figure 1]}

\section{Dependent variable}

Interpersonal conflict within organizations is endemic, and Ruekert and Walker (1987) have argued that conflict is likely to develop where there is a mix of collective goals, coupled with managers' self-interest, under conditions of interdependence. These are the conditions under which Marketing's CFRs are enacted, and there is good evidence that conflict in CFRs is common (e.g., Menon et al., 1996; Souder, 1981). Here, we define interpersonal conflict in the conventional sense - that it is unhealthy, and associated with dysfunctional behaviours.

Our focus on interpersonal conflict is consistent with structural contingency theory, because organizational performance is affected by a range of internal contingencies. Our focus is also consistent with interactionist studies of marketing's relationships (e.g., Morgan and Hunt, 1994; Ruekert and Walker, 1987), because conflict is one of the core constructs associated with the interaction approach.

\section{Independent variables}

\section{Use of lateral linkage devices}

Lateral linkage devices are used to improve integration between different departments (Olson et al., 1995). Various devices are advocated in the literature, e.g., the use of cross-functional teams, using "facilitators" to communicate directly with their counterparts in other departments, and placing staff temporarily in another functional area (e.g., Carroad and 
Carroad, 1982). The rationale for using these devices is that they can help improve crossfunctional coordination, reduce conflict, and improve CFRs (Maltz and Kohli, 2000).

Merging the sales and marketing units (departments)

Another structural mechanism used to improve integration is merging the marketing and sales units (Doyle, 1995). This can increase the physical proximity of marketing and sales staff, and also their frequency of interaction (Allen and Fustfeld, 1975). Greater Marketing/Sales interaction can increase their respective understanding of each other's work-related priorities and issues, and may improve the CFR.

\section{The firm being part of a large corporation}

Structural contingency theory suggests that a key variable affecting firms is the size of the organization - the larger the firm, the greater the imperative to differentiate structurally (Donaldson, 1996). One consequence of this is that in large firms, MMs and SMs may be in locations which are geographically distant. The opportunity for interaction is therefore reduced, and this separation may affect the Marketing/Sales CFR in large firms.

Training, experience, and education

Managers from different departments tend to differ in their training, work backgrounds, and education, and research shows that these differences may pose problems for forging effective CFRs (e.g., Weinrauch and Anderson, 1982). Consistent with this, Cespedes (1993) found that because marketing and sales personnel had very different training and work experiences, there was often little understanding of how the other operated, and resentment on both sides.

\section{Psychological distance}

Several studies of the Marketing/R\&D CFR have suggested that "sociocultural differences" between managers may be detrimental to cross-functional integration (e.g., Gupta et al., 1986). Drawing on this work, Fisher et al., (1997) examined the effects of "psychological distance" between MMs and engineers, and defined it in terms of how similar managers were in the time they took to make a decision, their tolerance for risk, the extent to which they focus on technology or customers, differences in their decision-making styles, and whether they believed there was always a "right" answer. High psychological distance may therefore be associated with less effective CFRs

\section{Communication frequency and bidirectionality}

Though it is widely accepted that communication is best viewed as being multidimensional, most prior research has only examined one dimension - communication frequency. So in order to give a more complete picture of cross-functional communication, we include two dimensions - communication frequency and bidirectionality. Here, we define communication frequency in terms of the intensity of information flow through media such as electronic mail, memos, and face-to-face meetings (Morgan and Piercy, 1998). Consistent with Fisher et al. (1997), we define bidirectionality as the degree to which communication between the MM and SM is a two-way process. In line with other literature on marketing's CFRs (e.g., Fisher et al., 1997) and sales's CFRs (e.g., Clare and Sanford, 1984), we argue that effective Marketing/Sales communication may help reduce interpersonal conflict in the CFR.

\section{Hypotheses Development}

Use of lateral linkage devices 
Firms that are structured along functional lines require re-integration into a cohesive whole (Lawrence and Lorsch, 1967). To facilitate this, organizations may use lateral linkage devices (e.g., cross-functional teams) to connect these departments (Olson et al., 1995). In their study of the Marketing/Engineering CFR, Shaw and Shaw (1998) found that engineers nominated organizational changes, clarification of functional roles, job rotation, and secondments as initiatives likely to reduce conflict between themselves and marketers. However, Maltz and Kohli (2000) had mixed results regarding the effectiveness of such devices, finding that cross-functional teams were effective in reducing marketing's conflict both at the SBU and functional levels, but not other devices such as formalisation, and spatial proximity of staff. Despite these results, we predict that greater use of these devices should help reduce conflict.

H1: As the use of the lateral linkage devices increases, conflict between the SM and MM decreases.

\section{Merging the sales and marketing units}

A common recommendation regarding marketing organization is that sales should be a part of marketing (e.g., Weitz and Anderson, 1981), whilst others have suggested that functional boundaries are likely to become increasingly irrelevant (Doyle, 1995). This implies that it may be advantageous for organizations to consider merging previously separate marketing and sales units to improve integration, and decrease conflict. Merging the two functions would provide opportunities for marketing and sales specialists to interact more frequently, to better understand each other's professional domain, and work more effectively together on joint projects. We therefore hypothesise:

H2: When the sales and marketing units have been merged, conflict between the SM and MM decreases.

\section{The firm being part of a large corporation}

Employees in large firms tend to be "corporate" in their behaviours, e.g., be less inclined to engage in conflict, and may even try to eliminate it altogether. Robbins (1974) noted that anticonflict values become part of an organization's culture, and conflict is viewed negatively. Managers therefore seek to avoid conflicts which disturb the status quo. Furthermore, managers in large firms are often evaluated and rewarded for a lack of conflict in their areas of responsibility. Accordingly, we argue that MMs and SMs in large firms will tend to minimise overt conflict.

In large firms it is also less likely that the MMs and SMs will be co-located, and there is strong empirical evidence that frequency of interaction reduces significantly as geographic distance increases (Allen and Fustfeld, 1975; Maltz and Kohli, 1996). Interaction theory however does not provide unequivocal guidance on the relationship between interaction frequency and conflict, and both a positive and a negative relationship could be predicted. There is also little empirical work to guide us on this issue, however, Maltz and Kohli (2000) found that physical proximity had no impact on conflict between marketing and R\&D, manufacturing, or finance. The standpoint we take here however, is that interpersonal conflict between MMs and SMs is likely to decrease as geographic distance increases, because when there is less interaction, there is less opportunity for conflict to arise. Empirical evidence supporting this argument was provided by Ruekert and Walker (1987). Accordingly, we hypothesise: 
H3: When the firm is part of a large corporation, conflict between the SM and MM decreases.

\section{Effects of training, work experience, and education}

Three variables-SMs' marketing training, MM's sales experience, and the SMs' level of formal education-are drawn from research examining differences in norms between marketing and manufacturing personnel that originate in differences in professional training and unique aspects of each function's work activities (e.g., Kahn and Mentzer, 1994). Shaw and Shaw (1998) found that when there were differences in education and vocational training between marketing managers and engineering managers, there was poor communication and an inadequate understanding of the other department, which often led to conflict. Accordingly, it seems reasonable to expect that when SMs have formal marketing training, conflict with MMs will be lower. Support for this contention is provided by Shaw and Shaw (1998) in which the respondent engineers suggested that their being given marketing training would be an important way to improve their relationship with marketing. Accordingly, we hypothesise:

H4: As the marketing training of the SM increases, conflict decreases.

Similarly, if two managers have similar work experience, this might benefit the CFR. A MM with prior sales experience for example is more likely to understand the SM's concepts, issues, and practices. This improved understanding of the SM's conceptual and operational domain may help them communicate and work more effectively with the MM, and reduce conflict. We therefore hypothesise:

H5: When the MM has greater sales experience, conflict decreases.

Few studies have examined the effects of education on cross-functional conflict. Lawrence and Lorsch (1967) noted however, that "training" (education) increases integration and decreases conflict between managers. Training helps peer managers understand the reasons behind differences in their respective orientations and behaviours. Therefore, where a SM has a good understanding of a MM's professional domain, this may help reduce conflict. SMs with higher levels of education are also more likely be university educated, and many university courses, even scientific/technical ones now require students to study business subjects such as marketing. Such SMs may therefore have a better understanding of the MM's concepts and priorities, leading to lower conflict. Moreover, managers with higher education are likely to have anti-conflict value systems, and seek to eliminate conflict in their areas of responsibility (Robbins, 1974). Accordingly we hypothesise:

H6: As the relative formal education of the SM increases, conflict decreases.

\section{Psychological distance}

Our argument here is that when two managers are psychologically distant from each other, they are likely to approach problems differently, and disagree on important issues. For instance, they may have different priorities, e.g., focusing on technology rather than customer needs, and value different types of information. We therefore argue that high psychological distance will be associated with higher interpersonal conflict. Thus, we hypothesise:

H7: As the psychological distance between SMs and MMs increases, conflict increases. 


\section{Communication frequency and bidirectionality}

As noted previously, interaction theory suggests that frequent communication can be associated with both dysfunctional and functional outcomes, and therefore no clear predictions can be made from this theory alone. Consistent with this, the empirical evidence on this issue is mixed. Souder's (1981) study of disharmony between marketing and R\&D found that increased interaction was associated with better cross-functional coordination. Similarly, communication frequency has been associated with greater mutual understanding and better rapport ( e.g., Menon et al., 1996).

In contrast, Maltz and Kohli (1996) found that beyond a certain threshold, frequent communication between peer managers is perceived to be low quality and dysfunctional. Similarly, Ruekert and Walker (1987) found that higher interaction flows between marketing and $R \& D$, and marketing and accounting were associated with increased conflict. Despite the mixed predictions from theory and the inconsistent empirical evidence, we posit that more frequent communication between MMs and SMs will lead to greater conflict, because this provides more opportunity for conflicts to arise.

H8: As the communication frequency increases between a SM and a MM, conflict increases.

Turning now to the effects of bidirectional communication on conflict, Fisher et al., (1997) found that bidirectionality was associated with higher perceived relationship effectiveness, a low conflict state. Another study examining cross-functional communication in interfirm relationships considered frequency and bidirectionality as underlying dimensions of a second-order factor - collaborative communication (Mohr et al., 1996). Their results show that collaborative communication had a strong positive effect on satisfaction with the relationship, again, a low conflict state. Further, Jablin (1979) found that bidirectional communication improves supervisor-subordinate relationships. In addition, "communication quality”, involving close, and informal communications is positively associated with crossfunctional integration, and the creative development of marketing strategy by intrafirm teams (Menon et al., 1999). Therefore, a collaborative form of communication such as bidirectionality should be associated with positive outcomes such as lower conflict. We therefore hypothesise:

H9: As communication bidirectionality increases between and a SM and a MM, conflict decreases.

\section{Method}

The sampling unit for this dyadic research was the SM. In order to provide a common general context for their answers, respondents were asked to focus on a specific, major crossfunctional project in which they, the MM, and staff from at least two other functional areas, were heavily involved during the previous 18 months. On average, 4.32 functional units were involved in these projects.

\section{Sample characteristics}

The sampling frame consisted of 716 firms in the UK and 325 firms in Australia. Analysis of the SIC codes revealed good diversity across the 201 responding firms. Goods-producing firms accounted for $65.9 \%$ of the responses, while service-providing firms made up the 
remaining $34.1 \%$. In terms of market type, $33.2 \%$ were in consumer markets, $40.8 \%$ were in business markets, and $26.0 \%$ sold to both types of market. The average firm size was 1787 employees.

\section{Data collection}

Data was collected from Australia and the UK using an identical, pretested, self-administered, mailed questionnaire. The sampling frame in each country was generated from a proprietary mailing list. The criteria for inclusion in the study were: (1) the firm should have an identified (named) SM/senior sales executive; and (2) there must also be a named MM/senior marketing executive. Executives with dual responsibilities were excluded from the study.

After one follow-up reminder letter, 201 questionnaires were returned, with one deemed unusable. Because it was anticipated that the mailing lists may not have been as accurate as the providers claimed, a stamped, self-addressed card was attached to each follow-up questionnaire, asking the respondent to choose one of five categories to represent their reason for not completing the questionnaire (e.g., there is nobody in my firm with the term "marketing" in their title). In the UK, a total of 113 questionnaires were returned, while 88 were returned in Australia. After allowing for the 92 organizations which had returned the postcards, our response rate was $20.3 \%$, which is comparable to the $19.9 \%$ response rate of Homburg et al., (1999), who also examined this sensitive topic of marketing organisation across two countries.

\section{Evaluating the quality of the data collected}

Tests of nonresponse bias revealed no significant differences between the early and late respondents in terms of individual-level variables-positional level, level of education, amount of marketing training, and organizational variables - goods vs service firms, the number of other divisions the sales force sells products for, and whether the firm is part of a large corporation.

Test of key informant competence. On average, the SMs had worked for 10.9 years in their firm, suggesting that they were knowledgeable about the issues covered. One respondent was eliminated from the analysis because she had only been with the firm for three weeks. The average duration of these Marketing/Sales CFRs was 3.6 years.

\section{Measurement invariance}

Inspection of the means, standard deviations, and alpha coefficients of the constructs suggested a close similarity between the UK and Australian data. To test this we conducted multi-group confirmatory factor analysis (cf. Mullen, 1995) using AMOS 4. Our results reveal equivalent factor structure across the two datasets, as all three tests pass. We also largely establish the equivalence of factor loadings, as two of the three tests pass, and one test failed marginally. In the strongest test of measurement invariance, equivalence of error variances, one of our three tests passed. We have therefore established "partial measurement invariance” (Byrne et al., 1989).

In many practical applications full metric equivalence is not present, however only partial metric equivalence is necessary for substantive analyses, providing that at least one item from each scale is metrically invariant (Steenkamp and Baumgartner, 1998). Our tests reveal that this criterion is met for all three of our reflective multi-item measures. Also, as our research involves combining and not comparing UK and Australian means, and because these means are very similar, we feel justified in pooling the two data sets for model testing. 


\section{Operational measures}

Our survey instrument included formative multi-item, reflective multi-item, and single-item measures. Our single item measures were: the level of the SM's marketing training; the level of the MM's sales experience, and the SM's level of formal education.

Two formative measures were used; the use of lateral linkage devices, and communication frequency. Drawing from the literature, we identified eight lateral linkage devices and operationalized this construct by forming a weighted index by multiplying the use of each device (measured by 1 or 0 ) by its effectiveness score. The scores for each of the eight items were totaled to form an index. In a similar manner, the ten communication frequency items were each viewed as representing a separate dimension and the scores for each item were totaled to form a composite index.

Three reflective measures were used: psychological distance; bidirectionality; and interpersonal conflict, and were assessed using exploratory and confirmatory factor analysis, and reliability analysis. Details of the measures can be found in the Appendix.

\section{Construct validity}

The reflective multi-item measures were first evaluated on the basis of item-to-total correlations and exploratory factor analysis. All three measures (14 items in total) were entered simultaneously into a principal components analysis with varimax rotation. The results revealed a three-factor solution explaining $63.71 \%$ of the variance, with all items loading cleanly onto their respective factors. As a result, we retained all 14 items for confirmatory factor analysis (CFA) using AMOS Version 4 (Arbuckle and Wothke, 1999).

Our CFA analysed a 14-item, three-factor model containing psychological distance (6 items), bidirectionality (4 items) and interpersonal conflict (4 items). Examination of the standardized regression weights suggested that one item from bidirectional communication should be deleted to improve construct validity.

The revised 13-item model produced a chi-square of 122.527 ( $\mathrm{df}=62, p=.000)$. Whilst the overall chi-square for this measurement model was significant $(\mathrm{p}<.01)$, other established measures of fit suggest good model fit. For example, the relative chi-square $\left(\chi^{2} / d f\right)$ was 1.976, and a rule of thumb for this statistic is that ratios in the range of 3 to 1 are indicative of an acceptable fit (e.g., Carmines and McIver, 1981). In addition, GFI = .912, AGFI = .871, TLI = .923 , CFI $=.938$, all of which approach or exceed the recommended .9 , and RMSEA $=.07$, which is below the .08 indicating acceptable model fit.

Discriminant validity was established, as the squared correlation between each pair of reflective constructs was less than the variance extracted for each individual construct (Fornell and Larcker, 1981). Reliability analysis revealed that the alpha coefficients for all but one of the scales are .77 or higher (see Appendix), suggesting a reasonable degree of internal consistency amongst the indicators. In addition, the average variance extracted for our reflective multi-item measures exceeds .50 , except psychological distance (AVE $=.42$ ). Overall, our results suggest that these multi-item measures have reasonable psychometric properties and appear suitable for substantive analysis and interpretation.

\section{[Take in Table I]}

\section{Analysis}

OLS regression was used to estimate our model and an examination of the residuals showed no obvious violations for the key assumptions of linearity, normality, and independence. More specifically, because multicollinearity of the predictors can be a problem in multiple regression, we estimated the variance inflation factors for each independent variable in the 
model. The values for these factors ranged from 1.06 to 1.55, which is below 2 and hence acceptable (cf. Maltz and Kohli, 2000; Mason and Perrault, 1991). Accordingly, multicollinearity was not a problem. Moreover, the Durbin-Watson statistic was 2.34, which suggests that adjacent observations are not correlated. As a rule of thumb, observed values between 1.5 and 2.5 are acceptable.

\section{Results}

Descriptive findings

Interpersonal conflict was assessed using 4 items and 7-point bipolar scales. Accordingly, the maximum possible score for this construct was 28. Because the overall mean for this construct was 10.05 (s.d. = 5.17), we can conclude that there is a surprisingly low level of interpersonal conflict between MMs and SMs in our sample. However, the relatively large standard deviation suggests that there is wide variation for the scores (minimum $=4.00$, maximum $=24.00$ ). The use of T-tests showed that there were no statistical differences across the population means for the two countries $(\mathrm{UK}$ mean $=10.08$, s.d. $=5.20$; Australia mean $=$ 10.01 , s.d. $=5.16$ ) or by type of product (goods mean $=10.51$, s.d. $=5.12$; services mean $=$ 9.53, s.d. = 5.52). The use of one-way ANOVA also showed that there were no differences in the levels of conflict according to market type (business mean $=10.32$, s.d. $=5.11$; consumer $=10.04$, s.d. $=4.74$; both markets mean $=9.65$, s.d. $=5.16$ ).

\section{Model testing}

Table II reports the results of the regression analysis, and as can be seen, six of the nine hypotheses are supported. Specifically, we found that the use of lateral linkage devices $\left(\mathrm{H}_{1}\right)$ was negatively associated with conflict. Similarly, we found that being part of a large corporation $\left(\mathrm{H}_{3}\right)$ had a negative impact on conflict. Moreover, we found that when SMs had greater formal education $\left(\mathrm{H}_{6}\right)$, there was less conflict with the MM. And as predicted for $\mathrm{H}_{7}$, we found that as psychological distance increased, there was more conflict. Importantly, both communication variables were highly statistically significant, and communication frequency $\left(\mathrm{H}_{8}\right)$ had a strong positive effect on conflict while bidirectionality $\left(\mathrm{H}_{9}\right)$ had a strong negative effect. The three non-significant hypotheses were: merging the sales and marketing units $\left(\mathrm{H}_{2}\right)$, SM's marketing training $\left(\mathrm{H}_{4}\right)$, and the MM's sales experience $\left(\mathrm{H}_{5}\right)$.

\section{[Take in Table II]}

\section{Theoretical implications}

Our model integrates constructs associated with structural contingency, and interaction theory to examine the antecedents of conflict in the Marketing/Sales CFR. In doing so we test the effects of various structural, individual, and communication variables on interpersonal conflict. Of these three groups of constructs, the two communication behaviours - communication frequency and bidirectionality have the strongest effects on interpersonal conflict. Consistent with one prediction of interaction theory, we find that frequent communication can increase conflict in the CFR. In contrast, bidirectionality has a strong negative impact on interpersonal conflict, perhaps because it is a collaborative, consultative form of communication.

The next strongest effects on interpersonal conflict were from the individual-level variables — psychological distance, and the SM's formal education. Our study reveals that differences in psychological make-up are a precursor to interpersonal conflict, corroborating theory which predicts that sociocultural and psychological differences act as barriers to crossfunctional integration (e.g., Fisher et al., 1997). Furthermore, we find that where SMs have 
more formal education, conflict is lower, which supports the argument that better educated managers are more likely to have anti-conflict value systems.

The findings also reveal that the level of the SM's marketing training and the MM's sales experience had no influence on interpersonal conflict. Whilst a number of CFR studies (e.g., Weinrauch and Anderson, 1982) have theorised that differences in work experience and training may be a cause of cross-functional conflict, our results do not support this contention. Our results are therefore consistent with Maltz and Kohli (2000) who found that the use of "multi-functional training" did not reduce conflict at the SBU level, nor at the departmental level. It may be that in existing, evolved relationships such as those in our sample, other factors (e.g., effective communications) are more important in reducing conflict than one's work and training background.

These results may be explained by social identity theory (e.g., Tajfel, 1978) which suggests that people derive a sense of identity and belonging from being part of particular group, e.g., being a member of the sales unit, or the marketing unit. Members of sales (or marketing) ingroups will tend to see themselves as different from, and hold negative stereotypes and biases against members of outgroups. Hence social identity theory would predict that there would be conflict between sales and marketing units. Our results suggest that where SMs have marketing training, and MM's have sales experience, that these are not sufficient to reduce a person's identification with their ingroup, and in turn, to reduce conflict in the CFR. Our findings are therefore also broadly consistent with Dewsnap and Jobber (2004), who found that the level of sales training and experience of marketing personnel, and the level of sales personnel's training and experience in marketing had no effect on Marketing/Sales collaboration.

Turning now to the structural variables, our major finding is that the use of lateral linkage devices reduces conflict between SMs and MMs. This finding supports recent research which found that senior management can influence the level of Sales/Marketing collaboration via formal policies, and also their behaviours, by being seen to value cooperation, collaboration, and teamwork (Dewsnap and Jobber, 2004).

Contrary to expectations, we found no relationship between firms merging the sales and marketing units, and reduced interpersonal conflict. This suggests that structural changes may not necessarily have a significant impact at the individual level. It may be that fundamental differences between personnel in the two functional units (e.g., psychological distance) are likely to persist, despite changes to organizational structure. Institutional theory (e.g., DiMaggio and Powell, 1983) suggests that social systems do not change as rapidly as their environments. Hence merely changing organizational structures will not necessarily have an immediate impact on internal relationships due to organizational inertia, and effects such as reduced interpersonal conflict may take considerable time to emerge.

Also, more potent effects on interpersonal conflict are probably to be expected at the individual level, e.g., via bidirectional communication. Our findings are therefore consistent with Ruekert and Walker (1987), who noted that the individual is the appropriate starting point for studying cross-functional interactions.

Our final theoretical implication relates to the wider applicability of our model. Whilst our model was tested in the context of the Marketing/Sales CFR, we believe that the model may apply equally to other Marketing CFRs, e.g., Marketing/R\&D, and to CFRs not involving marketing personnel, such as the Purchasing/Manufacturing CFR. We believe that the conceptual framework we employed, using structural, individual, and communication variables, examine issues that are fundamental to all CFRs. 


\section{Managerial implications}

Our findings have implications for both senior marketing executives and middle-level MMs who are directly involved in CFRs with SMs. In particular, one of the encouraging findings from this research is that contrary to anecdotal reports, and conceptual work in the academic literature, many firms in the UK and Australia appear to be managing this CFR quite well. However, there is significant variation in the level of conflict in this CFR, and our model testing provides insights into how to improve the MM/SM relationship. For example, it reveals the importance of effective communications in reducing conflict in CFRs. In particular, MMs should be aware that mere frequency of communication is likely to be ineffective, and rather than resolve conflict, it may actually increase it. In contrast, collaborative, consultative communications such as bidirectional communications can significantly reduce cross-functional conflict.

In addition, we find that training in your counterpart's discipline does not reduce conflict. It may be that such training, as suggested by Chang (2003), needs to be undertaken jointly (i.e., SMs and MMs together) rather than separately.

A final set of implications relates to the importance of individual differences in generating conflict. It might be advantageous for example, for firms to consider recruiting MMs and SMs who are similar psychologically, as such similarities seem to help reduce conflict between peer managers. In addition, our results provide some encouragement for senior management if the initial conditions for the Marketing/Sales CFR are not ideal, e.g., the MM and SM are quite psychologically distant. One important implication of our research is that effective communication between managers has a powerful effect in reducing conflict. Therefore, where MMs and SMs establish a pattern of bidirectional communication, this may eventually override the negative effects on the CFR of high psychological distance, and enable them to work more effectively together.

\section{Limitations and directions for future research}

A major limitation of our research is that it is restricted to SM's perceptions of the CFR. To better understand the Marketing/Sales CFR, future research will need to examine the relationship from the perspective of MMs. Ideally, however, researchers need to examine SMs and MMs simultaneously i.e., provide dyadic data.

Another limitation relates to our decision to examine only one psychosocial outcome, dysfunctional conflict. Future research could examine other psychosocial outcomes, such as perceived relationship effectiveness (e.g., Ruekert and Walker, 1987). In addition, research in the management and marketing literature has found that conflict can have functional as well as dysfunctional effects on CFRs (e.g., Menon et al., 1996). Future research could therefore examine the antecedents of this functional form of conflict. Finally, our measure of psychological distance was not ideal, with an average variance extracted $=.42$. Future research could incorporate a better measure of this important individual-level construct. 


\section{References}

Allen, T.J. and Fustfeld, A.R. (1975), "Research laboratory architecture and the structuring of communications,” R\&D Management, Vol. 5 No. 2, pp. 153-64.

Arbuckle, J.L. and Wothke, W. (1999), AMOS 4.0 User's Guide, Chicago, IL, SmallWaters Corporation.

Byrne, B.M., Shavelson, R.J. and Muthén, B. (1989), “Testing for the equivalence of factor covariance and mean structures: the issue of partial measurement invariance”, Psychological Bulletin, Vol. 105, May, pp. 456-66.

Carmines, E.G. and McIver, J.P. (1981), “Analysing models with unobserved variables”, in Bohrnstedt, G.W. and Borgatta, E.F. (Eds), Social Measurement: Current Issues, Beverly Hills, CA, Sage.

Carroad, P.A. and Carroad, C.A. (1982), "Strategic interfacing of R\&D and marketing”, Research Management, January, pp. 28-33.

Cespedes, F.V. (1993), “Coordinating sales and marketing in consumer goods firms”, Journal of Consumer Marketing, Vol. 10 No. 2, pp. 37-55.

Cespedes, F.V. (1994), “Industrial marketing: managing new requirements”, Sloan Management Review, Spring, pp. 45-60.

Clare, D.A. and Sanford, D.G. (1984), "Cooperation and conflict between industrial sales and production”, Industrial Marketing Management, Vol. 13, pp.163-9.

Dewsnap, B. and Jobber, D. (2000), “The sales-marketing interface in consumer packagedgoods companies: a conceptual framework”, Journal of Personal Selling and Sales Management, Vol. 20, Spring, pp. 109-19.

Dewsnap, B. and Jobber, D. (2002), “A social psychological model of relations between marketing and sales”, European Journal of Marketing, Vol. 36 No. 7/8, pp. 874-94.

Dewsnap, B. and Jobber, D. (2004), "The antecedents of sales-marketing collaboration: An empirical investigation”, Proceedings of the $33^{\text {rd }}$ Annual Conference of the European Marketing Academy, J.L. Munuera-Aleman (Ed), University of Murcia, Murcia, Spain, May 18-21, (CD-ROM).

DiMaggio, P.J. and Powell, W.W. (1983), “The iron cage revisited: institutional isomorphism and collective rationality in organizational fields", American Sociological Review, Vol. 48, April, pp. 147-60.

Donaldson, L. (1985), In Defence of Organization Theory: A Reply to the Critics, Cambridge, MA, Cambridge University Press. 
Donaldson, L. (1996), “The normal science of structural contingency theory”, in Clegg, S.R., Hardy, C. and Nord, W.R. (Eds), Handbook of Organization Studies, London, Sage, pp. 57-76.

Doyle, P. (1995), "Marketing in the new millennium”, European Journal of Marketing, Vol. 29 No. 13, pp. 23-41.

Fisher, R.J., Maltz, E. and Jaworski, B.J. (1997), "Enhancing communication between marketing and engineering: the moderating role of relative functional identification”, Journal of Marketing, Vol. 61, July, pp. 54-70.

Fornell, C. and Larcker, D.F. (1981), "Evaluating structural equation models with unobservable variables and measurement error”, Journal of Marketing Research, Vol. 18, February, pp. 39-50.

Gobeli, D.H., Koenig, H.F. and Bechinger, I. (1998), "Managing conflict in software development teams: a multilevel analysis", Journal of Product Innovation Management, Vol. 15, pp. 423-435.

Gupta, A.K., Raj, S.P, and Wilemon, D. (1986), "A model for studying the R\&D-marketing interface in the product innovation process," Journal of Marketing, Vol. 50, April, pp. 717.

Homburg, C., Workman, J.P. Jr., and Krohmer, H. (1999), “Marketing's influence within the firm”, Journal of Marketing, Vol. 63, April, pp. 1-17.

Houston, M.B., Walker, B.A. Hutt, M.D., and Reingen, P.H. (2001), "Cross-unit competition for a market charter: the enduring influence of structure”, Journal of Marketing, Vol. 65 No. 2, April, pp. 19-34.

Jablin, F.M. (1979), "Superior-subordinate communication: the state of the art", Psychological Bulletin, Vol. 86, pp. 1201-222.

Kahn, K.B. and Mentzer, J.T. (1994), "Norms that distinguish between marketing and manufacturing”, Journal of Business Research, Vol. 30, pp.111-18.

Kahn, K.B. and Mentzer, J.T. (1998), “Marketing's integration with other departments”, Journal of Business Research, Vol. 42, pp. 53-62.

Lawrence, P.R. and J.W. Lorsch (1967), Organization and Environment: Managing Differentiation and Integration, Boston, MA, Graduate School of Business Administration, Harvard University.

Maltz, E. and Kohli, A.K. (1996), "Market intelligence dissemination across functional boundaries”, Journal of Marketing Research, Vol. 33, February, pp. 46-61.

Maltz, E., and Kohli, A.K. (2000), "Reducing marketing's conflict with other functions: the differential aspects of integrating mechanisms”, Journal of the Academy Marketing Science, Vol. 28 No. 4, pp. 479-92. 
Mason, C.H. and Perrault, W.D. (1991), "Collinearity, power, and interpreation of multiple regression analysis”, Journal of Marketing Research, Vol. 28, August, pp. 268-80.

Menon, A., Bharadwaj, S.G., Adidam, P.T., and Edison, S.W. (1999), "Antecedents and consequences of marketing strategy making: a model and test”, Journal of Marketing, Vol. 63, April, pp. 18-40.

Menon, A., Bharadwaj, S.G. and Howell, R. (1996), "The quality and effectiveness of marketing strategy: effects of functional and dysfunctional conflict in intraorganizational relationships", Journal of the Academy of Marketing Science, Vol. 24 No. 4, pp. 299-313.

Moenaert, R.K., Souder, W.E., DeMeyer, A., and Deschoolmeester, D. (1994), "R\&Dmarketing integration mechanisms, communication flows, and innovation success", Journal of Product Innovation Management, Vol. 11, January, pp. 31-45.

Mohr, J.J., Fisher, R.J., and Nevin, J.R. (1996), "Collaborative communication in interfirm relationships: moderating effects of integration and control”, Journal of Marketing, Vol. 60, July, pp.103-15.

Morgan, N.A. and Piercy, N.F. (1998), "Interactions between marketing and quality at the SBU level: Influences and outcomes”, Journal of the Academy of Marketing Science, Vol. 26 No. 3, pp. 190-208.

Morgan, R.M. and Hunt, S.D. (1994), "The commitment-trust theory of relationship marketing”, Journal of Marketing, Vol. 58, July, pp. 20-38.

Mullen, M.R. (1995), "Diagnosing measurement equivalence in cross-national research", Journal of International Business Studies, Vol. 26 No. 3, pp. 631-54.

Olson, E.M., Walker, O.C. Jr. and Ruekert, R.W. (1995), "Organizing for effective new product development: the moderating role of product innovativeness”, Journal of Marketing, Vol. 59, January, pp. 48-62.

Pennings, J.M. (1992), “Structural contingency theory: a reappraisal”, in B.M. Staw and Cummings, I.I. (Eds), Research in Organizational Behavior, Vol. 14, pp. 267-309.

Pfeffer, J. (1982), Organizations and Organization Theory, Boston, MA, Pitman.

Pondy, L.R. (1967), “Organizational conflict: concepts and models”, Administrative Science Quarterly, Vol. 12, pp. 296-320.

Reid, D.A., Pullins, E.B., Plank, R.E., and Buehrer, R.E. (2004), "Measuring buyers' perception of conflict in business-to-business sales interactions", Journal of Business \& Industrial Marketing, Vol. 19 No. 4, pp. 236-49.

Robbins, S.P. (1974), Managing Organizational Conflict, Englewood Cliffs, NJ, PrenticeHall. 
Ruekert, R.W. and Walker, O.C. (1987), “Marketing’s interaction with other functional units: a conceptual framework and empirical evidence”, Journal of Marketing, Vol. 51, January, pp. 1-19.

Sarin, S. and Mahajan, V. (2001), "The effect of reward structures on the performance of cross-functional product development teams”, Journal of Marketing, Vol. 65, April, pp. 35-53.

Shaw, V. and Shaw, C.T. (1998), “Conflict between engineers and marketers”, Industrial Marketing Management, Vol. 27, pp. 279-91.

Souder, W.E. (1981), "Disharmony between R\&D and marketing”, Industrial Marketing Management, Vol. 10, pp. 67-73.

Steenkamp, J.E.M. and Baumgartner, H. (1998), "Assessing measurement invariance in cross-national consumer research”, Journal of Consumer Research, Vol. 25, June, pp. 78-90.

Tajfel, H. (1978), “Interindividual behaviour and intergroup behaviour”, in Tajfel, H. (Ed.), Differentiation Between Social Groups, London, Academic Press.

Weinrauch, J.D. and Anderson, R. (1982), “Conflicts between engineering and marketing units”, Industrial Marketing Management, Vol. 11, pp. 291-301.

Weitz, B. and Anderson, E. (1981), “Organizing the marketing function”, in Enis, B. and Roering, K. (Eds), Review of Marketing 1981, Chicago, American Marketing Association, pp. 134-42. 
Figure 1: Conceptual Model

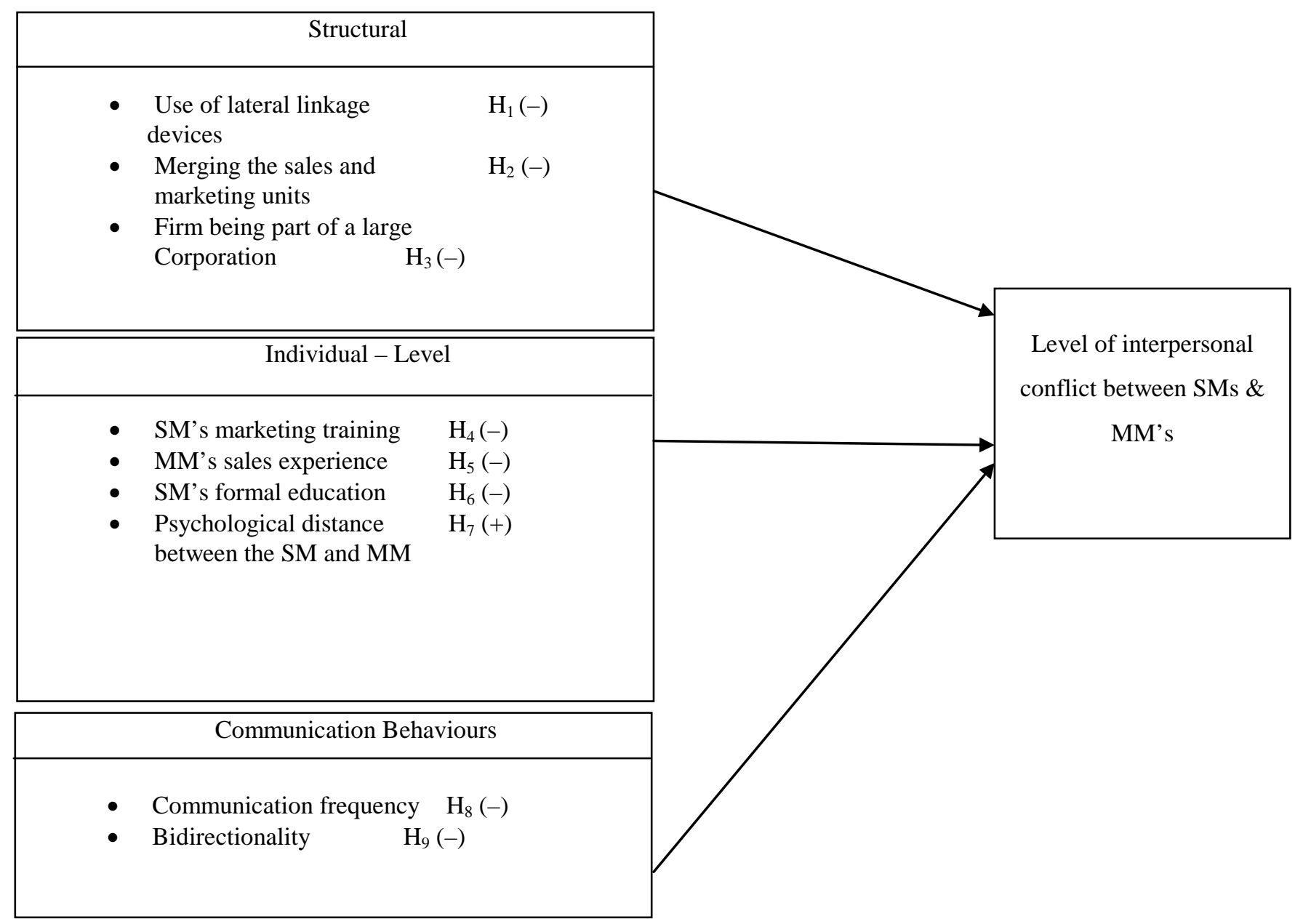


Table I

Descriptive statistics and intercorrelations ${ }^{a}$

\begin{tabular}{|l|l|l|l|l|l|l|l|l|l|l|}
\hline \multicolumn{1}{|c|}{ Variables } & $\begin{array}{l}\text { Scale } \\
\text { Mean }\end{array}$ & S.D. & 1 & 2 & 3 & 4 & 5 & 6 & 7 & 8 \\
\hline 1. Use of lateral linkage devices & $2.71^{\mathrm{b}}$ & .36 & - & & & & & & & \\
\hline 2. SM's marketing training & $3.84^{\mathrm{b}}$ & 1.82 & -.01 & - & & & & & & \\
\hline 3. MM's sales experience & $3.28^{\mathrm{b}}$ & 2.18 & .03 & -.12 & - & & & & & \\
\hline 4. SM's formal education & $2.93^{\mathrm{c}}$ & 1.01 & .02 & $.41^{*}$ & -.08 & - & & & & \\
\hline 5. Pyschological distance & & & & & & & \\
\hline 6. Communication frequency & $3.78^{\mathrm{b}}$ & 1.29 & -.14 & -.09 & $-.21^{*}$ & -.07 & - & & & \\
\hline 7. Bidirectionality & $3.06^{\mathrm{b}}$ & .75 & -.09 & .01 & .13 & .06 & -.04 & - & & \\
\hline 8. Interpersonal conflict & $2.51^{\mathrm{b}}$ & 1.29 & $-.29^{*}$ & -.06 & .03 & -.13 & $.42^{*}$ & $.23^{*}$ & $-.47^{*}$ & - \\
\hline
\end{tabular}

* Pearson correlation coefficients significant at $p \leq 0.01$ level (two-tailed test).

a The variables merging the sales \& marketing units and being part of a corporation were not included since are nominally scaled.

b Seven-point scale

c Five-point comparative scale

d Reverse-scaled 
Table II

Regression model for explaining interpersonal conflict

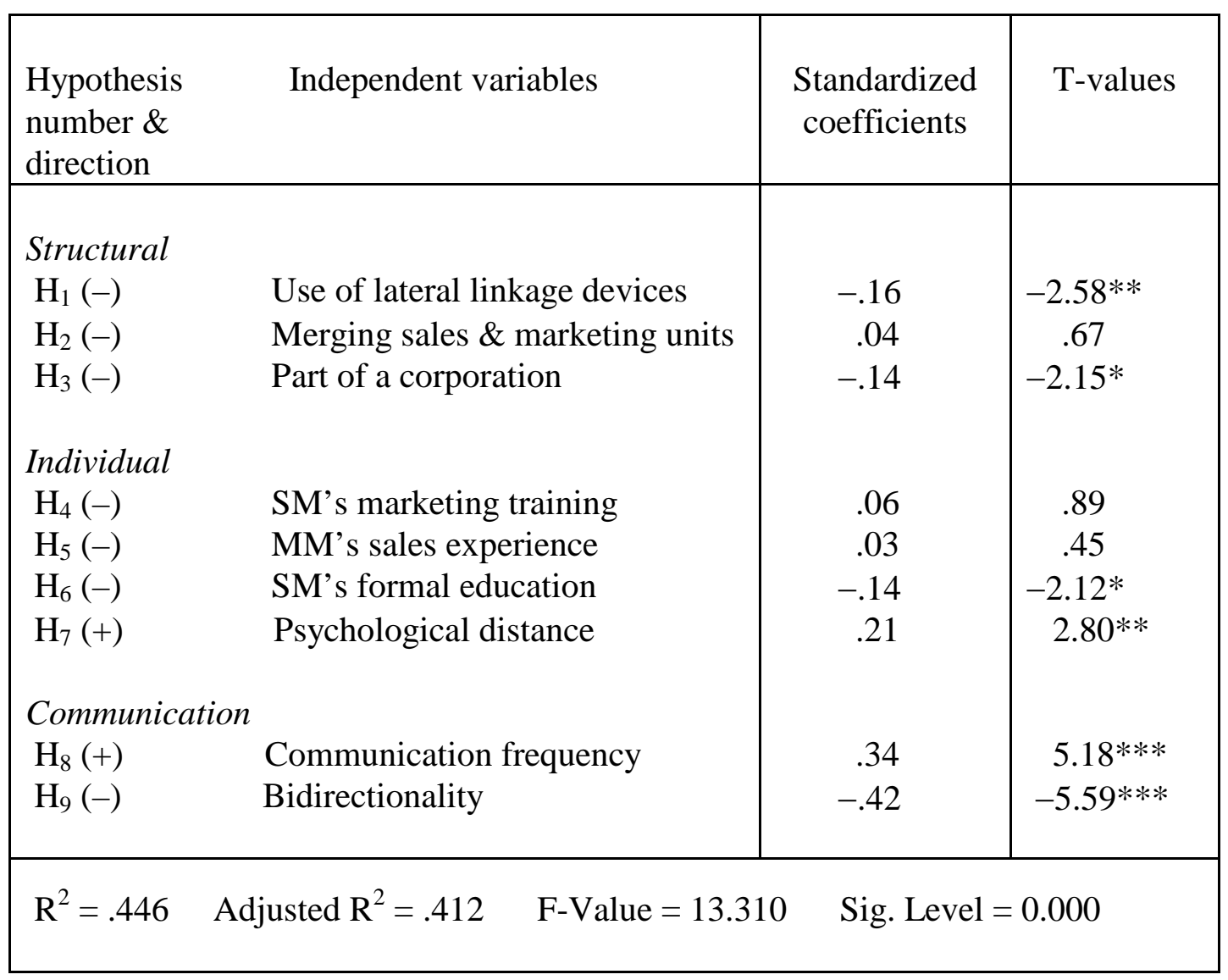

$* p \leq 0.05 * * p \leq 0.01 * * * p \leq 0.001$

One-tailed tests are used because the hypotheses are directional. 


\section{Endnote:}

i Respondents were asked: "How much emphasis does your firm place on differentiating its goods/services from competitors." A 7-point bi-polar scale anchored by 1 = "None at all" and 7 = "A great deal" was used. The mean score was 5.84 (s.d. =1.43), and $87.7 \%$ of the responses to this question were 5 or higher on this scale. Overall, these results indicate that the majority of the sampled firms were pursuing a differentiation strategy. 